\title{
Prostate-specific antigen-reactive cytotoxic $T$ lymphocyte precursors in colon cancer patients
}

\author{
YI WANG $^{1-3}$, MAMORU HARADA ${ }^{1,4}$, HIROHISA YANO ${ }^{5}$, SACHIKO OGASAWARA $^{5}$, \\ MASAHIRO TANAKA ${ }^{4}$, AKIRA YAMADA ${ }^{1,2}$ and KYOGO ITOH $^{1,2,4}$ \\ ${ }^{1}$ Cancer Vaccine Development Division, Kurume University Research Center for Innovative Cancer Therapy; \\ ${ }^{2}$ Center of the 21 st Century COE Program for Medical Science, Kurume University, Japan; ${ }^{3}$ Institute of Frontier Medical \\ Science, Jilin University, No.13 Xinmin Street, Changchun 130021, P.R. China; Departments of ${ }^{4}$ Immunology and \\ ${ }^{5}$ Pathology, Kurume University School of Medicine, Asahi-machi 67, Kurume 830-0011, Japan
}

Received August 4, 2005; Accepted September 29, 2005

\begin{abstract}
Prostate-specific antigen (PSA) is a representative of the prostate-related antigens, and has been considered to be a tumor marker of prostate cancer. However, some studies suggest that PSA could be produced by several types of tumors. In the present study, we attempted to determine whether or not PSA could be a target molecule in specific immunotherapy for patients with colon cancer. Five colon cancer cell lines were examined for their PSA expression at the mRNA and protein levels by RT-PCR and immunocytostaining, respectively. As a result, four cell lines were found to be positive for PSA at both the mRNA and protein levels. We also attempted to determine whether PSA-reactive cytotoxic $\mathrm{T}$ lymphocytes (CTLs) could be induced from the peripheral blood mononuclear cells (PBMCs) of HLA-A24+ colon cancer patients by in vitro stimulation with PSA-derived peptides. As a consequence, PSA peptide-specific CTLs could be generated from the PBMCs of male and female colon cancer patients. Their cytotoxicity against HLA-A24+ PSA-expressing colon cancer cells was dependent on HLA class I-restricted and $\mathrm{CD}^{+} \mathrm{T}$ cells. These findings indicate that PSA-reactive CTL precursors are present in the periphery of colon cancer patients, and that PSA could be a target molecule in specific immunotherapy to colon cancer.
\end{abstract}

\section{Introduction}

Prostate-specific antigen (PSA) is a 33-kD glycoprotein belonging to the kallikrein family of proteases (1). Besides serving as a tumor marker for prostatic carcinoma (2-6), PSA

Correspondence to: Dr Mamoru Harada, Department of Immunology, Kurume University School of Medicine, 67 Asahimachi, Kurume, Fukuoka 830-0011, Japan

E-mail: haramamo@med.kurume-u.ac.jp

Key words: prostate-specific antigen, colon cancer, cytotoxic $\mathrm{T}$ lymphocytes, peptide has also been employed as a target molecule in immunotherapy for prostate cancer (7-10). Although PSA was originally believed to be prostate-specific, expression of PSA gene and/ or PSA protein has been detected at a low level in some extra- prostatic tissues such as normal breast tissue, breast tumors, breast milk, female serum, endometrium, adrenal neoplasm, lung tissue, and renal cell carcinomas (11-18). In addition, PSA was detected in colon cancer tissues of both male and female patients (19). A high level of PSA was detected in a colon cancer patient who showed no evidence of prostate cancer, and PSA concentrations returned to normal levels after total removal of the cancer (20). Analysis of preoperative serum PSA concentrations of female colorectal carcinoma patients revealed that total PSA has a tendency to be present in aggressive histological types and in advanced-stage tumors, but that free PSA was predominantly detected in well-differentiated and early-stage tumors (21). These lines of evidence suggest that PSA might be immunogenic in colon cancer patients. In this study, we investigated the PSA expression in colon carcinoma cell lines and attempted to determine whether PSA-reactive CTLs could be induced from male and female colon cancer patients.

\section{Materials and methods}

Cell lines. The colon cancer cell lines used were: colo201, colo205, colo320, SW480, and SW620. The control LNCaP is a prostate cancer cell line. All tumor cell lines were maintained in RPMI-1640 medium supplemented with $10 \%$ FCS. C1R-A2402 is an HLA-A*2402-expressing subline of C1R lymphoma (Dr M. Takiguchi, Kumamoto University, Japan), and was cultured in RPMI-1640 medium supplemented with $10 \% \mathrm{FCS}$ and $500 \mu \mathrm{g} / \mathrm{ml}$ hygromycin B (Gibco BRL, NY).

Peptides. PSA ${ }_{152-160}$ (CYASGWGSI), PSA $248-257$ (HYRKWI KDTI) (9), influenza (Flu) virus-derived (RFYIQMCYEL), Epstein-Barr virus (EBV)-derived (TYGPVFMCL), and human immunodeficiency virus (HIV)-derived (RYLRQQLLGI) peptides were used, all with the binding motif to HLA-A24 


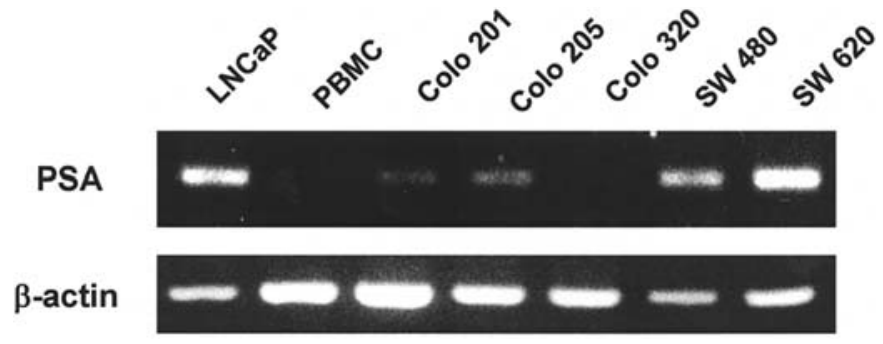

Figure 1. Expression of PSA mRNA in colon cancer cell lines. The expression of PSA mRNA in five colon cancer cell lines was examined by the RT-PCR method. B-actin was used as a control. A prostate cancer cell line $\mathrm{LNCaP}$ and the PBMCs of a healthy donor were used as the positive and negative controls, respectively.

molecules. All peptides were purchased from Biologica Co., Nagoya, Japan, and were dissolved with DMSO at a concentration of $10 \mathrm{mg} / \mathrm{ml}$.

$R T-P C R$. The total RNA was isolated from different cell lines with RNA-Bee ${ }^{\mathrm{TM}}$ (Tel-Test, Inc.) according to the manufacturer's instructions. cDNA was synthesized from $5 \mu \mathrm{g}$ total RNA. PSA cDNA was detected by PCR amplification using a set of oligonucleotide primers specific to PSA (5'-AC CAAGTTCATGCTGTGTGC-3' and 5'-TGATCCACTTCC GGTAATGC-3'). PCR was performed in 30 cycles ( $1 \mathrm{~min}$ at $95^{\circ} \mathrm{C}, 1 \mathrm{~min}$ at $60^{\circ} \mathrm{C}$, and $1 \mathrm{~min}$ at $72^{\circ} \mathrm{C}$ ) using Taq DNA polymerase (Promega Corp). The PCR product was sizefractionated on $2 \%$ agarose gel.

Immunocytostaining. The expressions of PSA protein in colon cancer cell lines were examined by immunocytostaining on smear slides. Anti-PSA mouse monoclonal antibody (mAb) (Dako) was used with a catalyzed signal amplification system kit (Dako). The prostate cancer cell line LNCaP was used as a positive control.

Induction of peptide-specific CTLs. PBMCs ( $1 \times 10^{5}$ cells/ well) of HLA-A24+ colon cancer patients were incubated with $10 \mu \mathrm{g} / \mathrm{ml}$ of each peptide in a U-bottom 96-well microculture plate (Nunc, Denmark) at a volume of $200 \mu 1$ of culture medium. The culture medium consisted of $45 \%$ RPMI-1640, 45\% AIM-V medium (Gibco BRL), 10\% FCS, $100 \mathrm{U} / \mathrm{ml}$ of interleukin-2 (IL-2), and $40 \mu \mathrm{g} / \mathrm{ml}$ gentamycin. Half of the culture medium was removed and replaced with new medium containing $20 \mu \mathrm{g} / \mathrm{ml}$ corresponding peptide every 3-4 days. On day 15, half of the cultured cells were separated into four wells; two wells were mixed with the corresponding peptide-pulsed C1R-A2402 cells, and the other two wells with the HIV peptide-pulsed C1R-A2402 cells. After an 18-h incubation, the supernatants were collected and examined for the IFN- $\gamma$ level by ELISA. The background IFN- $\gamma$ production in response to the HIV peptide was subtracted from the value given in the data.

Assay of cytotoxicity. After in vitro stimulation with the PSAderived peptide, peptide-stimulated PBMCs were cultured for approximately 10 days to obtain a sufficient number of cells for the cytotoxicity assay. The cell-mediated cytotoxicity assays were performed using a standard $6-\mathrm{h}{ }^{51} \mathrm{Cr}$ release assay.
Table I. Induction of PSA peptide-specific CTLs from the PBMCs of colon cancer patients.

\begin{tabular}{lccccc}
\hline & \multicolumn{5}{c}{ Peptide } \\
\cline { 3 - 6 } Patient & Gender & PSA $_{152-160}$ & PSA $_{248-257}$ & EBV & Flu \\
\hline & & & IFN- $\gamma(\mathrm{pg} / \mathrm{ml})$ \\
1 & Female & 20 & $\underline{\underline{303}}$ & 0 & ND \\
2 & Male & $\underline{128}$ & $\underline{50}$ & 10 & ND \\
3 & Female & 4 & $\underline{34}$ & $\underline{274}$ & 41 \\
4 & Female & $\underline{59}$ & $\underline{52}$ & 27 & 6 \\
5 & Male & 12 & 10 & ND & ND \\
\hline
\end{tabular}

The PBMCs of HLA-A24+ colon cancer patients were stimulated in vitro with the $\mathrm{PSA}_{152-160}$ or $\mathrm{PSA}_{248-257}$ peptide in quadruplicate, as described in Materials and methods. Thereafter, the cultured PBMCs were tested for their reactivity to C1 R-A2402 cells that had been pre-pulsed with the $\mathrm{PSA}_{152-160}, \mathrm{PSA}_{248-257}$, or the control HIV peptide. Values represent IFN- $\gamma$ production by the effector PBMCs in response to C1 R-A2402 cells that were pre-pulsed with the PSA peptide. Backgroud IFN- $\gamma$ production in response to the HIV peptide was subtracted. Significant values $(\mathrm{P}<0.05$ by the twotailed Student's t-test) are underlined. ND, not done.

A total of $1 \times 10^{3}{ }^{51} \mathrm{Cr}$-labeled target cells were cultured with effecter cells in U-bottom 96-well plates in triplicate wells. To eliminate nonspecific lysis, the cytotoxic activity was tested in the presence of a 40 -fold excess of unlabeled K562 cells. In the antibody-blocking experiments, either anti-HLA class I (W6/32: mouse IgG2a), anti-HLA-DR (L243: mouse IgG2a), anti-CD4 (NU-TH/I: mouse IgG1), anti-CD8 (NU-TS/C: mouse IgG2a), or anti-CD14 (H14: mouse IgG2a) mAb was added into the wells at a dose of $20 \mu \mathrm{g} / \mathrm{ml}$ at the initiation of the assay.

Statistics. The statistical significance of the data was determined using a two-tailed student's t-test. A p-value of $<0.05$ was considered statistically significant.

\section{Results}

Expression of PSA in colon carcinoma cell lines. The expression of PSA mRNA in colon carcinoma cell lines was investigated by the RT-PCR method (Fig. 1). The mRNA expression of PSA was detected in 4 of 5 colon carcinoma cell lines. The level of PSA mRNA expression in SW480 and SW620 was comparable to that in the LNCaP prostate cancer cell line. The expression of PSA protein was further investigated by immunocytostaining analysis (Fig. 2). The expression of PSA protein was found in the nuclei of colo201, colo205, SW480, and SW620. The expression of PSA protein was also found in the cytoplasm of colo205. No positive staining was observed in colo320 (data not shown).

Induction of PSA peptide-specific CTLs from the PBMCs of colon cancer patients. We next determined whether or not PSA peptide-reactive CTLs could be induced from the PBMCs of two male and three female colon cancer patients (Table I). 

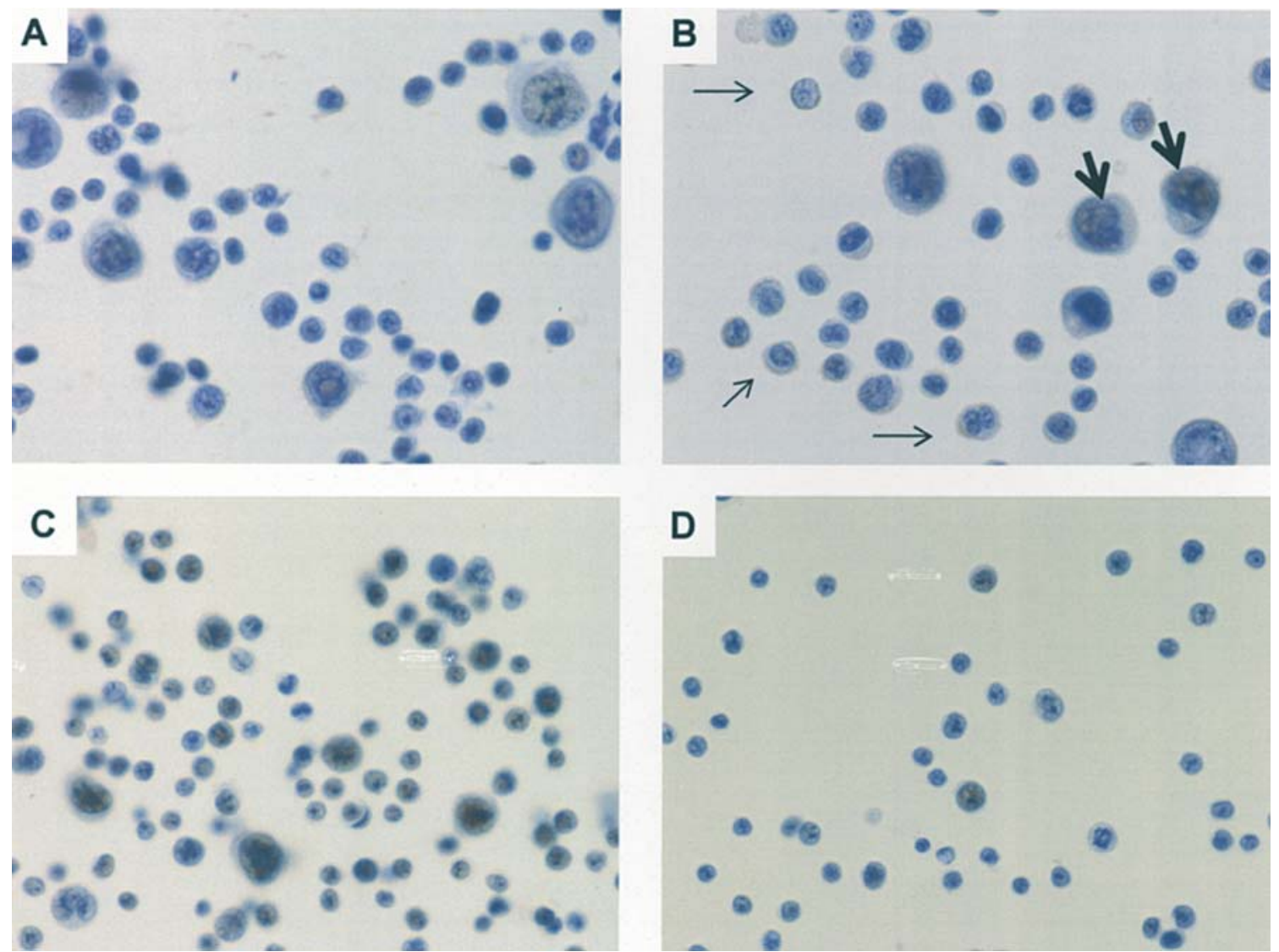

Figure 2. Immunocytostaining of colon cancer cell lines. Expression of the PSA protein in colon cancer cell lines was evaluated by immunostaining on cell smear with anti-PSA mAb. Positive reactions were observed in the nuclei of colo201 (A), colo205 (B), SW480 (C), and SW620 (D). A weak positive reaction in the cytoplasm (thin arrows) and the nuclei (thick arrows) was also observed in some colo205 cells (B).

Because we have previously identified that the $\operatorname{PSA}_{152-160}$ and $\mathrm{PSA}_{248-257}$ peptides can potentially generate PSA-reactive CTLs from HLA-A24+ prostate cancer patients (9), these two PSA-derived peptides were employed in this experiment. The PBMCs of five HLA-A24+ colon cancer patients were stimulated in vitro with the $\mathrm{PSA}_{152-160}$ or $\mathrm{PSA}_{248-257}$ peptide, and were then examined for their HLA-A24-restricted IFN- $\gamma$ production using C1R-A2402 cells. The HLA-A24-binding EBV and Flu peptides were used as positive controls, and the HLA-A24-binding HIV peptide was used as a negative control. As a result, the PSA $_{152-160}$ peptide-specific CTLs were generated from the PBMCs of one male and one female colon cancer patien (Pts. 2 and 4), and PSA $248-257$ peptide-specific CTLs were generated from the PBMCs of one male and two female colon cancer patients (Pts. 1, 2, and 4). These results indicated that PSA-reactive CTL precursors exist in the PBMCs of male and female colon cancer patients.

Cytotoxicity of PSA peptide-specific CTLs against colon cancer cells. We further investigated whether PSA peptide-specific CTLs could show cytotoxicity against PSA ${ }^{+}$HLA-A24expressing colon cancer cells. After the IFN- $\gamma$ assay, PSA peptide-stimulated PBMCs were cultured with IL-2 alone for an additional 2 weeks, they were examined for their cytotoxicity against colon cancer cells (Fig. 3A). The PSA peptide-specific CTLs induced from two colon cancer patients (Pts. 1 and 2) showed significantly higher levels of cytotoxicity against HLA-A24+ ${ }^{+}$and PSA-expressing SW480 cells than against HLA-A24- and PSA-expressing colo205 cells and HLA-A24+ and the PSA-negative colo320 cells. We further examined the cells responsible for the cytotoxicity using blocking antibodies. As shown in Fig. 3B, the cytotoxicity of PSA peptide-specific CTLs against SW480 cells was significantly inhibited by the addition of anti-CD8 or antiHLA class I mAb, but not by that of anti-CD4, anti-CD14, or anti-HLA class II mAb. These results indicated that HLA class I-restricted $\mathrm{CD}^{+}$CTLs that were generated from the PBMCs of colon cancer patients showed cytotoxicity against HLA-A24+ and PSA-expressing SW480 colon cancer cells.

\section{Discussion}

PSA is a representative of prostate-related antigens, and its capacity of serving as a target molecule in specific immunotherapy for prostate cancer has been investigated by several research groups. Several MHC class I-restricted or MHC class II-restricted PSA-derived T-cell epitopes have been identified, and their potentiality in peptide-based immunotherapy for prostate cancer has been suggested (22-24). We also identified PSA-derived peptides having the potential to generate prostate cancer-reactive CTLs (9), and have conducted peptide-based vaccine against prostate cancer (25). On the other hand, several researchers have revealed that the expression of PSA gene and/or PSA protein has been detected at low levels in some extraprostatic normal and cancer tissues 
A
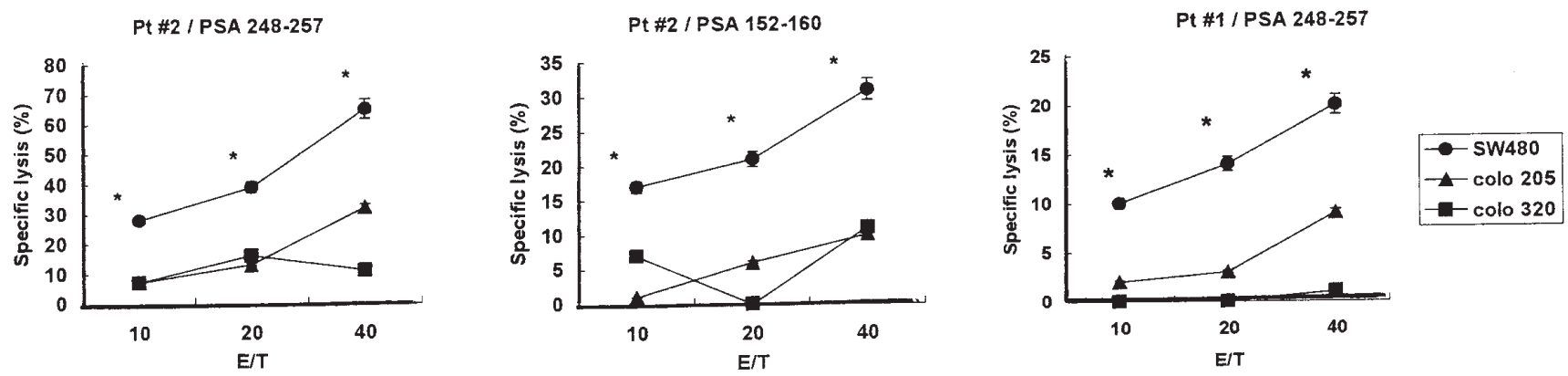

B
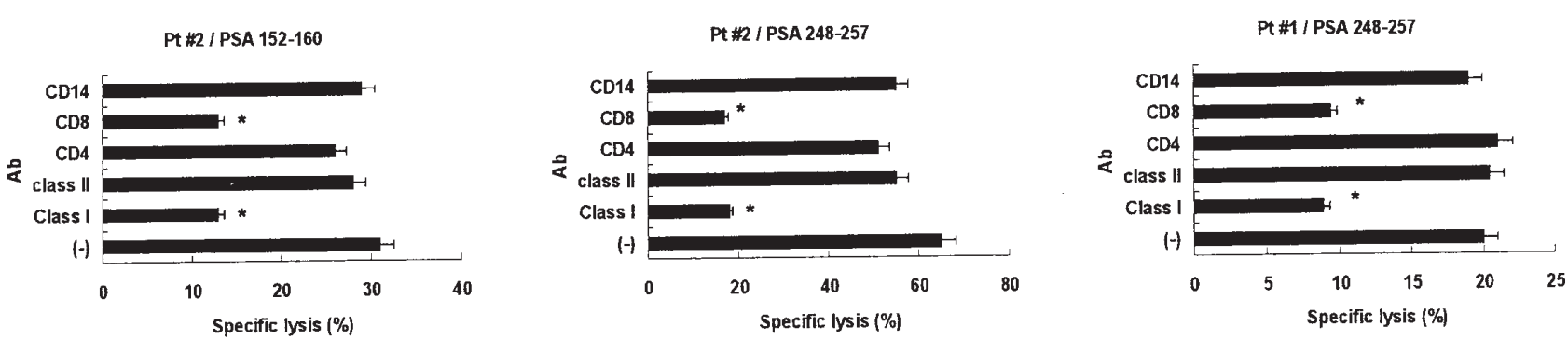

Figure 3. Cytotoxicity of PSA peptide-specific CTLs against colon cancer cells. (A) Cytotoxicity of PSA peptide-stimulated PBMCs was examined. The PBMCs of two colon cancer patients (Pts. 1 and 2) were stimulated in vitro with the PSA $_{152-160}$ or PSA $_{248-257}$ peptide, as described in the Materials and methods, and their cytotoxicity was examined by a $6-\mathrm{h}^{51} \mathrm{Cr}$-release assay. $\mathrm{PSA}^{+} / \mathrm{HLA}-\mathrm{A} 24^{+} \mathrm{SW} 480, \mathrm{PSA}^{+} / \mathrm{HLA}-\mathrm{A} 24^{-}$colo205, and PSA-/HLA-A24 ${ }^{+}$colo320 were used as targets. (B) The cytotoxicity of PSA peptide-induced CTLs was examined in the presence of mAb. The PSA peptide-stimulated PBMCs were tested for their cytotoxicity against PSA $/$ HLA-A24 ${ }^{+}$SW480 in the presence of the mAb indicated. Values represent the means of triplicate determinants, and statistical analysis was performed by a two-tailed Student's t-test $\left({ }^{*} \mathrm{P}<0.05\right)$.

(11-18). It has been suggested that androgens, glucocorticoids, mineralocorticoids, and progestins up-regulate PSA production, but that oestrogens indirectly down-regulate the PSA production induced by androgens (26-28). Androgen, progesterone, and oestrogen receptors seem to exist and be expressed in colorectal cancer tissues (29-32). Duraker et al reported that the levels of free PSA in female colorectal carcinoma patients are significantly higher than those of healthy women, indicating the existence of PSA in colon cancer tissues (21). In addition, PSA has been detected in colon cancer tissues of both male and female patients (19). Furthermore, high levels of PSA have been detected in a colon cancer patient who showed no evidence of prostate cancer, with the PSA concentrations returning to normal levels after total removal of the cancer (20). These lines of evidence led us to examine the expression of PSA in colon cancer cell lines and further to determine its immunogenicity in colon cancer patients. Consequently, we found that considerable percentages of colon adenocarcinoma cell lines are positive for PSA. The RT-PCR analysis showed PSA mRNA expression in four of five colon adenocarcinoma cell lines. Immunocytostaining analysis revealed the expression of PSA protein in the nuclei of four colon cancer cell lines and the cytoplasm of one colon cancer cell line.

In the present study, we further investigated whether PSA peptide-specific and cancer-reactive CTLs could be induced from the PBMCs of HLA-A24+ colon cancer patients. The result was that $\mathrm{PSA}_{152-160}$ or $\mathrm{PSA}_{248-257}$ peptide-specific CTLs were induced from two or three of five colon cancer patients, respectively. The following ${ }^{51} \mathrm{Cr}$-release assay results indicated that these PSA peptide-stimulated CTLs lysed PSA-expressing colon carcinoma cell in an HLA-restricted manner, and that the cytotoxicity of these CTLs was dependent on HLA class Irestricted and $\mathrm{CD}^{+} \mathrm{T}$ cells. Although additional studies with relatively large numbers of cancer patients are needed, our findings suggest that PSA can be a target molecule in specific immunotherapy for colon cancer patients.

Thus far, a number of tumor-related antigens recognized by the immune system have been identified, and some of them are non-mutated self-antigens (33), of which PSA is a representative. Although some studies suggest that PSA could be expressed in extraprostatic normal tissues (13-18), this antigen is basically a non-self antigen in females. When PSAexpressing tumors develop in female patients, this antigen might be vulnerable to the immune system as a non-self antigen. We demonstrated that PSA peptide-specific CTLs are successfully induced from the PBMCs of female colon cancer patients. It may be that PSA is a better target molecule in female colon patients than in male colon patients. Either way, PSA may be a promising target molecule in specific immunotherapy for colon cancer patients.

\section{Acknowledgements}

This study was supported in part by Grant-in-Aids from the Ministry of Education, Science, Sports and Culture of Japan 
(No. 12213134 to K.I. and Research Center of Innovative Cancer Therapy of 21th Centry COE Program for Medical Science to K.I.), and from the Ministry of Health, Labor and Welfare, Japan (No. H14-trans-002, 11-16, and H12-cancer004 to K.I., and No.15-17 to M.H.).

\section{Reference}

1. Stenman UH, Leinonen J, Zhang WM and Finne P: Prostatespecific antigen. Semin Cancer Biol 9: 83-93, 1999.

2. Oesterling JE: Prostate specific antigen: a critical assessment of the most useful tumor marker for adenocarcinoma of the prostate. J Urol 145: 907-923, 1991.

3. Epstein JI: PSA and PAP as immunohistochemical markers in prostate cancer. Urol Clin North Am 20: 757-770, 1993.

4. Armbruster DA: Prostate-specific antigen: biochemistry, analytical methods, and clinical application. Clin Chem 39: 181-195, 1993.

5. Bostwick DG: Prostate-specific antigen. Current role in diagnostic pathology of prostatic cancer. Am J Clin Pathol 102: S31-S37, 1994.

6. Roos AK, Pavlenko M, Charo J, Egevad L and Pisa P: Induction of PSA-specific CTLs and anti-tumor immunity by a genetic prostate cancer vaccine. Prostate 62: 217-223, 2005.

7. Ploch NR and Brawer MK: How to use prostate-specific antigen. Urology 43: 27-35, 1994.

8. Pavlenko M, Roos AK, Lundqvist A, et al: A phase I trial of DNA vaccination with a plasmid expressing prostate-specific antigen in patients with hormone-refractory prostate cancer. $\mathrm{Br} \mathbf{J}$ Cancer 91: 688-694, 2004.

9. Harada M, Kobayashi K, Matsueda S, Nakagawa M, Noguchi M and Itoh K: Prostate-specific antigen-derived epitopes capable of inducing cellular and humeral responses in HLA-A24+ prostate cancer patients. Prostate 57: 152-159, 2003.

10. Perambakam S, Xue BH, Sosman JA and Peace DJ: Induction of Tc2 cells with specificity for prostate-specific antigen from patients with hormone-refractory prostate cancer. Cancer Immunol Immunother 51: 263-270, 2002.

11. Clements J, Ward G, Kaushal A, Hi SI, Kennett C and Nicol D: A prostate-specific antigen-like protein associated with renal cell carcinoma in women. Clin Cancer Res 3: 1427-1431, 1997.

12. Takahashi T, Hoshi S, Satoh M, Kaneda T, Suzuki KI, Nakagawara KI and Orikasa S: The study of PSA gene expression on urogenital cell lines. Int J Urol 6: 526-531, 1999.

13. Breul J, Pickl U and Hartung R: Prostate-specific antigen in urine. Eur Urol 26: 18-21, 1994.

14. Yu H and Diamandis EP: Prostate-specific antigen in milk of lactating women. Clin Chem 41: 54-58, 1995.

15. Yu H and Diamandis EP: Measurement of serum prostatespecific antigen levels in women and in prostatectomized men with an ultrasensitive immunoassay technique. J Urol 153: 1004-1008, 1995.

16. Yu H, Giai M, Diamandis EP, et al: Prostate specific antigen is a new favorable prognostic indicator for women with breast cancer. Cancer Res 55: 2104-2110, 1995.
17. Diamandis EP and Yu H: Nonprostatic sources of prostatespecific antigen. Urol Clin North Am 24: 275-282, 1997.

18. Zarghami N, D'Costa M, Tsuyuki D, Asa SL and Diamandis EP: Expression of the prostate specific antigen gene by lung tissue. Clin Cancer Res 3: 1201-1206, 1997.

19. Levesque M, Hu H, D'Costa M and Diamandis EP: Prostatespecific antigen expression by various tumors. J Clin Lab Anal 9: 123-128, 1995.

20. Yamamoto M, Hibi H and Miyake K: Raised prostate-specific antigen in adenocarcinoma of the colon. Int Urol Nephrol 29: 221-225, 1997.

21. Duraker N, Can D and Parilti M: Measurement of serum total and free prostate-specific antigen in women with colorectal carcinoma. Br J Cancer 86: 203-206, 2002.

22. Correale P, Walmsley K, Nieroda C, Zaremba S, Zhu M, Schlom J and Tsang KY: In vitro generation of human cytotoxic $\mathrm{T}$ lymphocytes specific for peptides derived from prostatespecific antigen. J Natl Cancer Inst 89: 293-300, 1997.

23. Xue BH, Zhang Y, Sosman JA and Peace DJ: Induction of human cytotoxic $\mathrm{T}$ lymphocytes specific for prostate-specific antigen. Prostate 30: 73-78, 1997.

24. Corman JM, Sercarz EE and Nanda NK: Recognition of prostate specific antigenic peptide determinants by human CD4 and CD8 T cells. Clin Exp Immunol 114: 166-172, 1998.

25. Noguchi M, Itoh K, Yao A, et al: Immunological evaluation of individualized peptide vaccination with a low dose of estramustine for HLA-A24+ HRPC patients. Prostate 63: 1-12, 2005.

26. Yu H, Diamandis EP, Zarghami N and Grass L: Induction of prostate specific antigen production by steroids and tamoxifen in breast cancer cell lines. Breast Cancer Res Treat 32: 291-300, 1994.

27. Zarghami N, Grass L and Diamandis EP: Steroid hormone regulation of prostate-specific antigen gene expression in breast cancer. Br J Cancer 75: 579-588, 1997.

28. Levesque MA, Clark GM, Yu H and Diamandis EP: Immunofluorometric analysis of p53 protein and prostate-specific antigen in breast tumors and their association with other prognostic indicators. Br J Cancer 72: 720-727, 1995.

29. Meggouh F, Lointier P, Pezet D and Saez S: Status of sex steroid hormone receptors in large bowel cancer. Cancer 67: 1964-1970, 1991.

30. Singh S, Sheppard MC and Langman MJS: Sex differences in the incidence of colorectal cancer: an exploration of oestrogen and progesterone receptors. Gut 34: 611-615, 1993

31. Korenaga D, Orita H, Maekawa S, Hasaka H, Ikeda T and Sugimachi K: Relationship between hormone receptor levels and cell-kinetics in human colorectal cancer. Hepatogastroenterology 44: 78-83, 1997.

32. Korenaga D, Orita H, Okuyama T, Kinoshita J, Maekawa S, Ikeda T and Sugimachi K: Sex hormone-receptor-negative tumors have a higher proliferative activity than sex hormonereceptor-positive tumors in human adenocarcinomas of the gastrointestinal tract. Surg Today 28: 1007-1014, 1998.

33. Renkvist N, Castelli C, Robbins PF and Parmiani G: A listing of human tumor antigens recognized by $\mathrm{T}$ cells. Cancer Immunol Immunother 50: 3-15, 2001. 